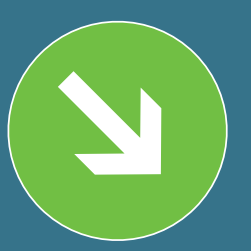

Ключевые слова: зажимное устройство, шестикулачковый патрон, маятниковая компенсация

\section{ФИКСАЦИЯ БЕЗ ДЕФОРМАЦИИ И БЫСТРАЯ НАЛАДКА}

\author{
Маркус МИХЕЛЬБЕРГЕР, Соня АУФРЕХТ
}

Предложен зажим заготовок с помощью шестикулачкового патрона с маятниковым механизмом компенсации и системой быстрой смены и настройки кулачков. Рассмотрены основные преимущества данной зажимной системы - сокращение времени наладки и высокая точность позиционирования.
Зажимные устройства серьезно влияют на точность и экономичность производства компонентов редукторов. Чтобы достичь максимальной гибкости и эффективности производства, компания ROLLSTAR AG инвестировала в приобретение шестикулачкового патрона с маятниковым механизмом компенсации и системой быстрой смены и настройки кулачков (рис. 1). Это удобное решение, экономящее время на подготовку к работе и дающее неизменно превосходный результат всегда - быстрее и экономичнее, чем зажимы обычной конструкции.

Компания ROLLSTAR AG использует на своем предприятии в Эглисвиле (Швейцария, кантон Aргау) шестикулачковые патроны с маятниковой компенсацией SCHUNK ROTA NCR 1250 большого размера, установленные на токарных станках Pittler PV 1600, для производства зубчатых колес (рис. 2).

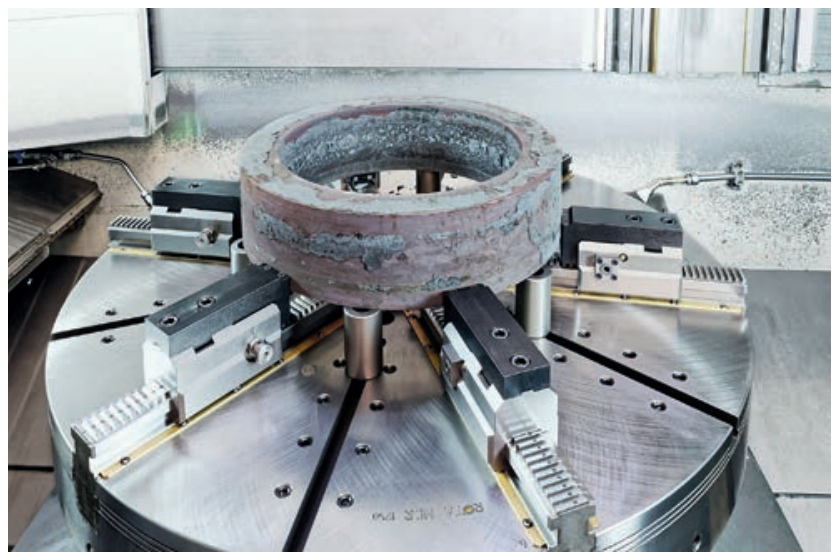

Стоило ли вкладываться в новое оснащение? «Определенно, да», - говорит Кристиан Мерки (Christian Märki), директор по закупкам и член расширенной группы управления компании ROLLSTAR. «Особенности конструкции станка в целом и зажимных устройств в частности, позволили нам вдвое сократить время наладки перед работой и на 75\% уменьшить процент брака». Особенно заметен эффект от инвестиций при производстве тонкостенных изделий и при точной обработке высококачественных материалов. «Компания стремилась достичь определенного уровня качества, сократить время производства и снизить общую стоимость двухступенчатого производства деталей, чувствительных к деформациям, сохранив при этом технологическую надежность», - говорит Мерки. Детали, которые раньше производили на станках с трехкулачко-

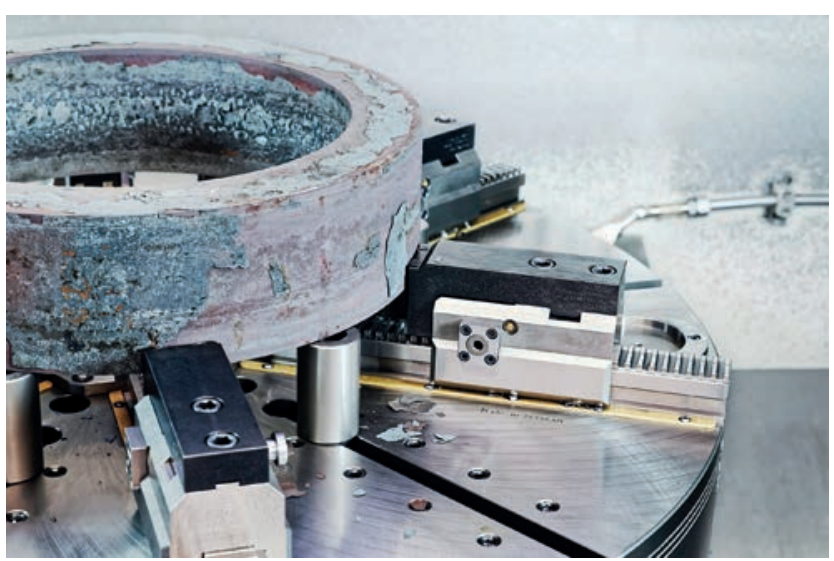

PUc. 1. Маятниковые кулачки патрона SCHUNK ROTA NCR 1250 обеспечивают оптимальное центрирование заготовки при фиксации. Во время фиксации кулачки упираются на специальные опоры, что гарантирует их оптимальное размещение 
выми патронами с двумя уровнями зажимного давления, теперь изготавливают на станках с патронами SCHUNK ROTA NCR быстрее, точнее и надежнее. «Если раньше мы зажимали коронную шестерню Ø820 мм в трехкулачковом патроне, ее деформация превышала 0,1 мм. Теперь же, когда кольцо зажимается в патроне ROTA NCR, деформация не превышает 0,02-0,03 мм. Столь высокая точность повышает срок службы редукторов, поскольку подшипники в нем теперь работают под полностью равномерной нагрузкой», приводит пример Мерки. Иными словами, редукторы служат гораздо дольше без дополнительного обслуживания и крайне редко выходят из строя внезапно. Редукторы ROLLSTAR ценятся за высочайшую надежность и работают в горной и забойной технике, где внеплановый простой стоит очень дорого.

\section{КОНСТРУКЦИЯ, РАЗРАБОТАННАЯ ЭКСПЕРТАМИ}

В разработке концепции данного зажимного устройства приняли активное участие специалисты по патронам для токарных станков компаний ROLLSTAR, PITTLER и SCHUNK, расположенных в городе Менген. Они приняли во внимание особенности обрабатываемых изделий, проектные требования и необходимость быстрой наладки оборудования перед работой. Решающим фактором в пользу решения, предложенного компанией SCHUNK, стало сочетание шестикулачковой быстросменной конструкции патрона с возможностью быстрой регулировки и возможности компании SCHUNK быстро представить готовый продукт. Кроме того, в правильности сделанного выбоpa компанию ROLLSTAR убедили отзывы других клиентов SCHUNK.

\section{ФИКСАЦИЯ БЕЗ ДЕФОРМАЦИЙ}

Шестикулачковый патрон с маятниковой компенсацией SCHUNK ROTA NCR состоит из центрального цилиндра со встроенными маятниковыми рычагами, расположенными под углом $120^{\circ}$ друг к другу. Каждый маятниковый рычаг соединен с двумя нижними кулачками. Таким образом, заготовка центрируется по шести попарно регулируемым точкам зажима. Поскольку все зажимные силы направлены к центру патрона, то заготовка центрируется без перекашивания. Патрон идеально охватывает заготовку благодаря возможности поворота кулачков. В сочетании с традиционным кулачковым зажимным механизмом такая конструкция гарантирует максимальную радиальную точность обработки заготовки и ее центрирование.

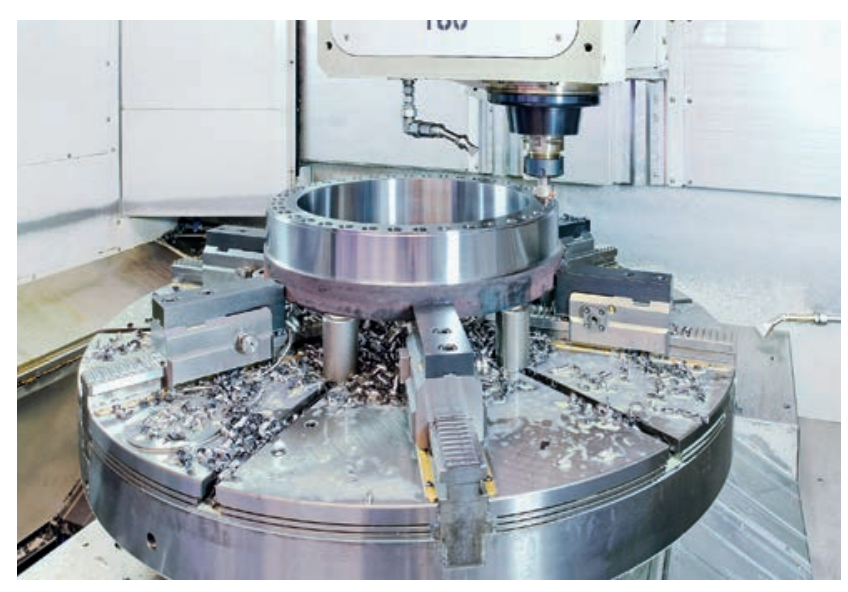

Puc. 2. Компания ROLLSTAR применяет патрон SCHUNK ROTA NCR 1250 для фиксации обрабатываемых деталей редукторов, которые не терпят даже малейшей деформации. Благодаря этому точность обработки оказывается гораздо выше, чем при использовании обычных трехкулачковых патронов

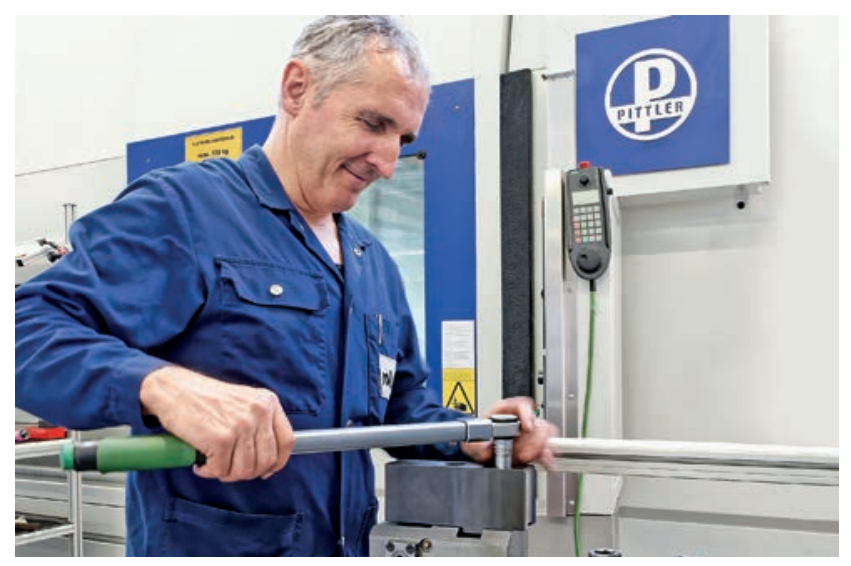

Puc. 3. Оператор станка Вилли Уммель настраивает второй набор кулачков, не дожидаясь полной остановки станка

\section{БЫСТРАЯ СМЕНА КУЛАЧКОВ}

Интерфейс кулачков патрона ROTA NCR полностью совместим с кулачками стандартной конструкции. Быстрая смена кулачков экономит время, способствует реализации затратных решений и сокращает время наладки перед работой. Встроенная система быстрой смены кулачков минимизирует время наладки и простоя станка (рис. 4). «Мы пользуемся двумя комплектами базовых кулачков, к тому же, накладные кулачки устанавливаются вне станка, то есть, пока на станке еще идет обработка», - поясняет руководитель рабочей группы Даниэль Фирц (Daniel 


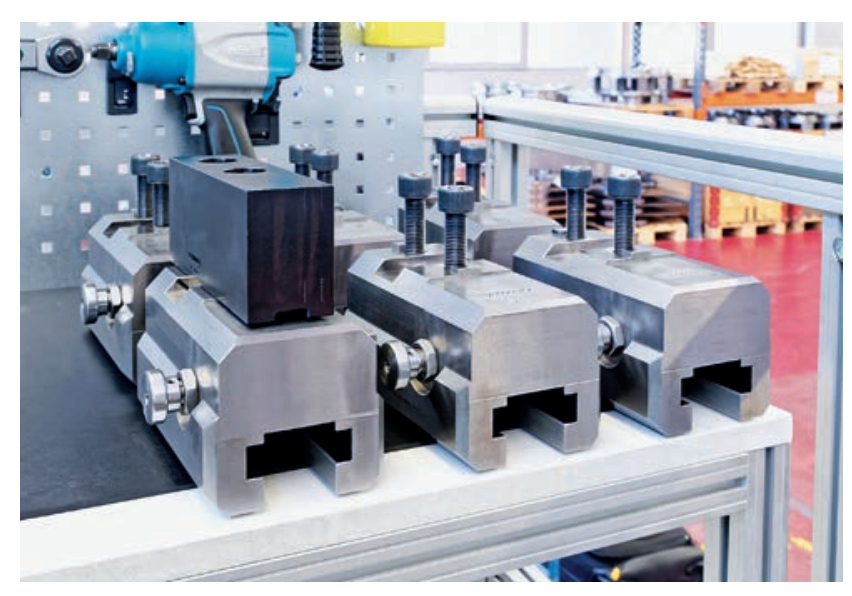

Puc. 4. Базовые кулачки патрона налажены вне станка и их можно заменить даже во время его работы

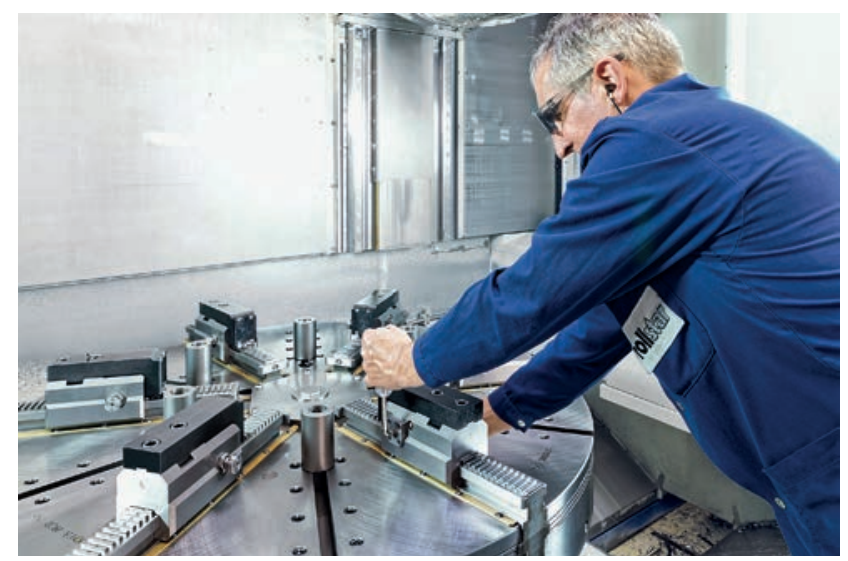

Puc. 5. Система быстрой смены и настройки кулачков, наладка станка занимает не более 20 мин

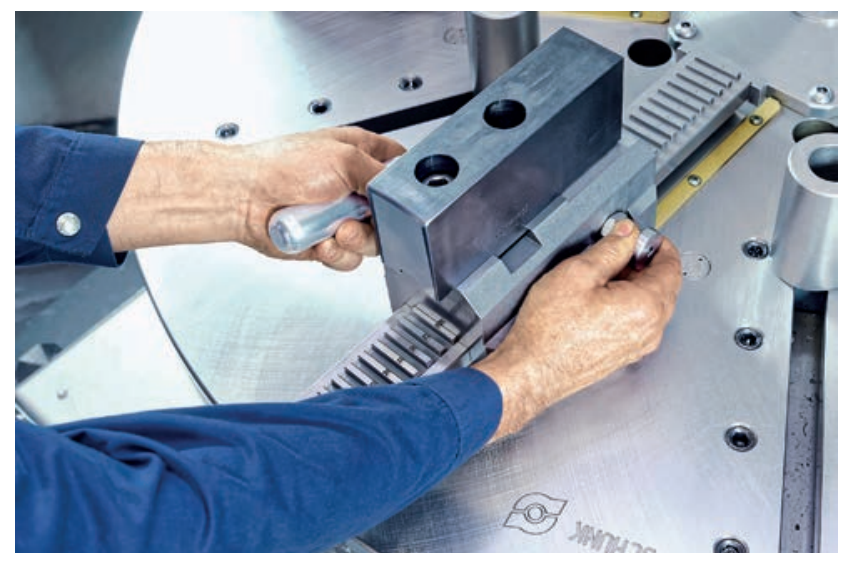

Puc. 6. Система быстрой смены кулачков позволяет поменять заранее настроенные базовые и накладные кулачки за несколько простых движений. Точность позиционирования кулачков можно контролировать по встроенной шкале
Fierz). «Благодаря этому процедура подготовки ко второй рабочей операции занимает всего 20 мин, включая чистку станка» (рис. 5, 6). Для этого нужно вставить базовые кулачки так, чтобы они автоматически зафиксировались в нужном положении, после чего затянуть винты крепления на четверть оборота динамометрическим ключом. Таким образом, система быстрой настройки кулачков позволяет настроить положение базовых кулачков в несколько простых этапов. «Система быстрой настройки позволяет регулировать размер фиксации с заранее установленным шагом, - поясняет оператор станка Вилли Уммель (Willy Ummel). - Система работает безупречно, к тому же, ее легко чистить». Раньше, когда применялись обычные патроны, переналадка станка для работы с заготовками другого размера занимала до двух часов рабочего времени. Теперь же Уммель тратит на это не больше получаса. Для фиксации черновой заготовки предусмотрен комплект накладных закаленных кулачков с зубчатыми вставками; для обработки детали с другой стороны предусмотрены мягкие накладные кулачки с отверстиями разного диаметра.

\section{ROLLSTAR AG}

Компания ROLLSTAR AG, расположенная в Эглисвиле (Швейцария, кантон Аргау), специализируется на разработке, проектировании и производстве компактных приводов с крутящим моментом от 1500 до 6500000 Нм. Компания производит стандартизированные модели блочных гидравлических моторов и планетарных редукторов, которыми комплектуется продукция ROLLSTAR. Кроме того, компания производит механизмы первичной и вторичной стороны и специальные редукторы на заказ. Приводы ROLLSTAR применяются в технике, работающей на строительстве дорог и метро, прокладке тоннелей, строительстве котлованов для размещения установок по переработке компоста и органических отходов в биогаз, в трубогибных станках для строительства трубопроводов и ветряных турбин, прокладке кабелей, устройстве проколов под коммуникации и т.п. Компания поддерживает запас продукции, что позволяет ей быстро комплектовать заказы. Благодаря такому подходу стандартные запасные части доставляются в любой международный аэропорт в любой точке мира всего за 72 ч. В компании трудятся около 60 человек. Более $90 \%$ продукции компании идет на экспорт. 

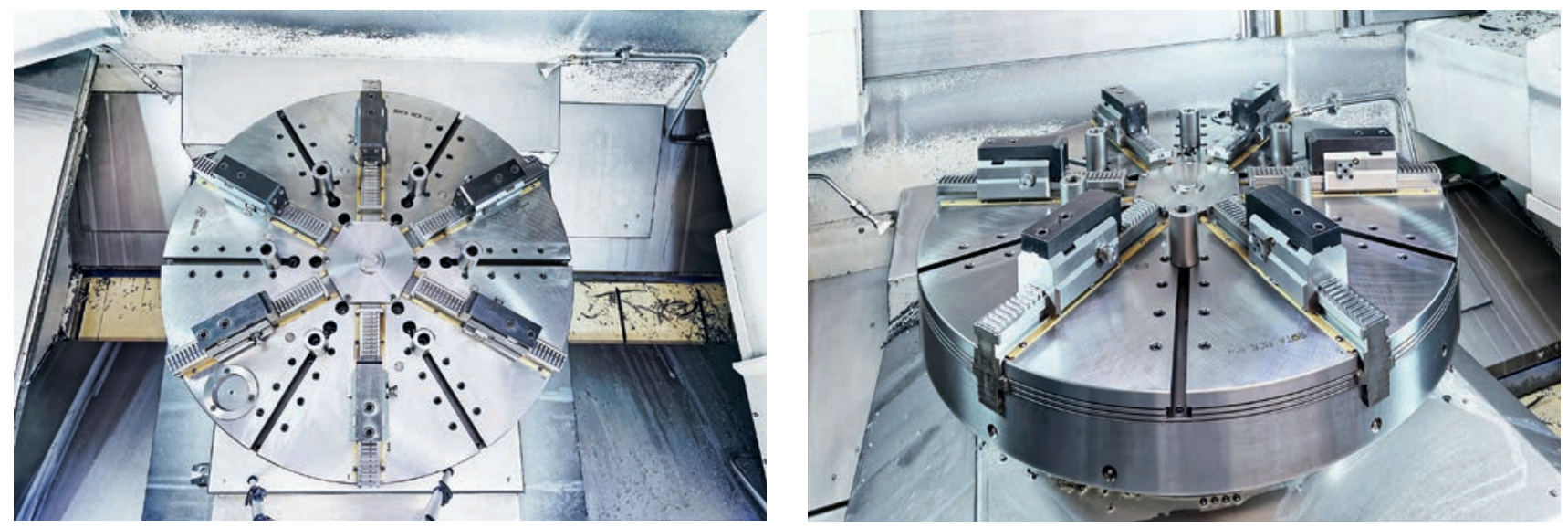

Puc. 7. Шесть маятниковых кулачков гарантируют оптимальное центрирование заготовки

\section{ИДЕАЛЬНОЕ БИЕНИЕ - НА 75\% МЕНЬШЕ БРАКА}

«Одной из основных целей вложений было добиться, чтобы станок работал как можно равномернее, без перерывов», - говорит руководитель рабочей группы Даниэль Фирц. «Патрон оказался настолько точным, что теперь мы можем снова и снова пользоваться одними и теми же кулачками без необходимости переточки». Даже после замены кулачков радиальное биение составляет около 0,02 мм, без каких-либо дополнительных настроек (рис. 7). Важную роль играет вертикальное положение шпинделя. Максимальная свобода движения, а вместе с ней и оптимальное центрирование, обеспечивается еще и тем, что заготовки опираются на шлифованные подставки, а не на кулачки патрона, как в станках с горизонтальных шпинделем (рис. 8). «Вертикальное расположение шпинделя станка гарантирует куда луч- шую точность вращения, поскольку в шпинделе, расположенном горизонтально, трение между заготовкой и кулачками мешает работе маятникового механизма», - подчеркивает Фирц. Закрепляя заготовку для первичной или финишной обработки, оператор Вилли Уммель может переводить маятниковый механизм патрона ROTA NCR в центрирующее положение, чтобы все шесть кулачков работали синхронно и в едином концентрическом направлении. Внедрение такой конструкции патрона имеет замечательный побочный эффект: количество брака упало примерно на $75 \%$. В первую очередь, это произошло из-за меньшей деформации заготовки, высокой точности смены кулачков и улучшения качества обработки поверхности заготовок. Меньший процент брака экономит немало средств, особенно при обработке ценных материалов, например, ферритовых сплавов, которые компания ROLLSTAR часто использует в своих изделиях.

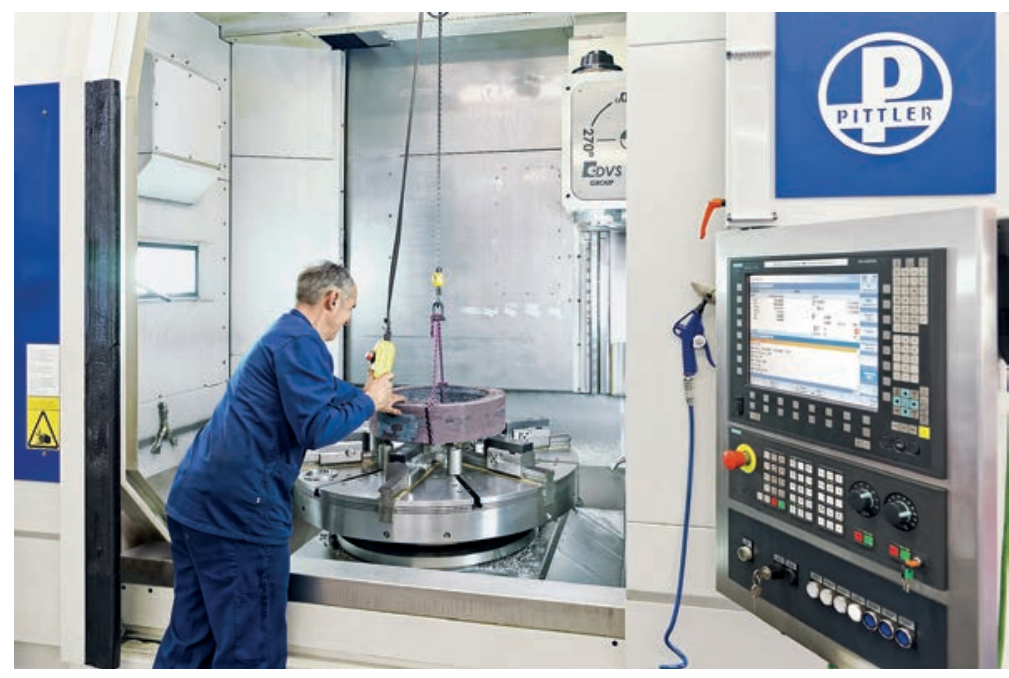

Puc. 8. Загружаемая в станок заготовка сначала ставится на специальные опоры. Это обеспечивает оптимальную ориентацию всех шести кулачков патрона

\section{ТЕХНОЛОГИЧЕСКАЯ ГИБКОСТЬ}

По словам директора по закупкам Кристиана Мерки (рис. 9), главным преимуществом новой зажимной системы является технологическая гибкость, которую получает производство компании ROLLSTAR. «Обычно мы производим изделия партиями по 10 шт., но теперь можем брать срочные заказы практически в любой момент, не нарушая общей производительности». Благодаря этому, компания смогла сократить наличные запасы, не потеряв в качестве обслуживания. В ближайшем будущем компания ROLLSTAR планирует начать применять новый патрон при обработ- 


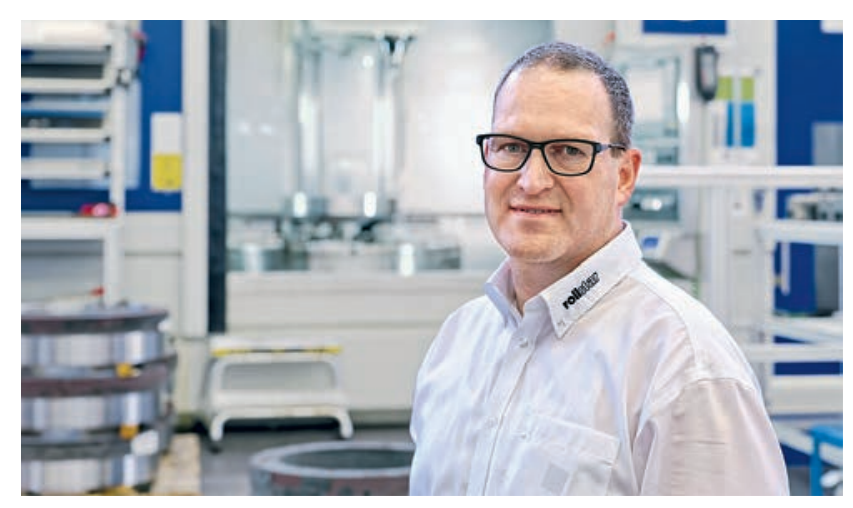

Puc. 9. Кристиан Мерки, директор по закупкам и член расширенной группы управления компании ROLLSTAR AG. «Целью вложений было повысить скорость, эффективность и технологическую гибкость производства. Мы добились радиальной точности в пределах от 0,02 до 0,03 мм при обработке заготовки диаметром 820 мм»

ке заготовок диаметром от 400 до 1600 мм. Конструкция патрона ROTA NCR 1250 идеально подходит для работы с заготовками такого размера. «Патрон удобно чистить, он быстро настраивается, и в нем очень легко крепить заготовку, потому что он расположен горизонтально», - делится Мерки.

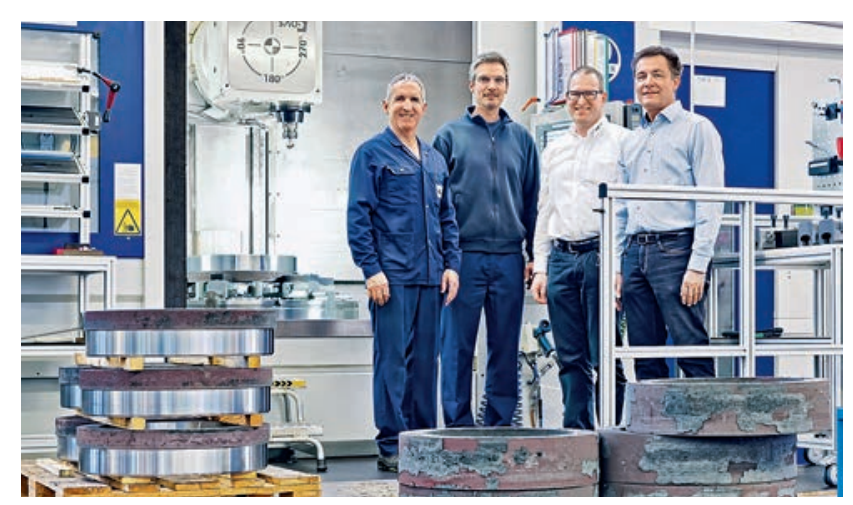

Puc. 10. В реализации проекта компании ROLLSTAR помогали специалисты компании SCHUNK. Ha фото (слева направо: оператор станка Вилли Уммель, руководитель рабочей группы Даниэль Фирц, директор по закупкам Кристиан Мерки и Рональд Рамп, генеральный директор SCHUNK Intec в Швейцарии

\section{МИХЕЛЬБЕРГЕР Маркус -}

глава отдела продаж систем зажима

\section{АУФРЕХТ Соня -}

дипломированный специалист по экономике предприятий (BA), журналист (FJS), менеджер по корпоративным коммуникациям и связям с общественностью

\section{НОВЫЕ КНИГИ ИЗДАТЕЛЬСТВА «ТЕХНОСФЕРА»}

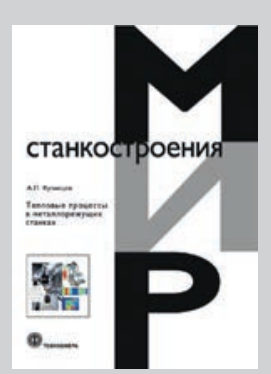

Цена 1090 руб.

\section{ТЕПЛОВЫЕ ПРОЦЕССЫ}

\section{В МЕТАЛЛОРЕЖУЩИХ СТАНКАХ}

\section{Кузнецов А.П.}

В книге рассматриваются методы оценки теплового режима металлорежущих станков и их наиболее теплонапряженных деталей и узлов. Приведен механизм формирования и теплофизического анализа теплового режима деталей и узлов металлорежущих станков, дана их теплофизическая классификация и описываются типовые тепловые модели. Приводятся аналитические зависимости для оценки стационарного и нестационарного теплового режимов деталей и узлов станков.

Приведена классификация методов воздействия на тепловой режим станков, описаны способы снижения, коррекции, компенсации и управления тепловым режимом металлорежущих станков.

Предлагаемая монография может быть полезна студентам, аспирантам, а также инженерам и специалистам, занимающимся вопросами повышения точности при проектировании, производстве и эксплуатации металлорежущих станков. 


\section{НОВЫЕ КНИГИ ИЗДАТЕЛЬСТВА «ТЕХНОСФЕРА»}

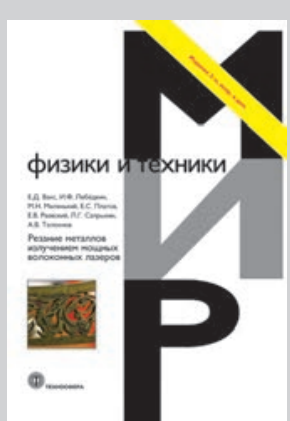

Цена 920 руб

\section{РЕЗАНИЕ МЕТАЛЛОВ ИЗЛУЧЕНИЕМ МОЩНЫХ ВОЛОКОННЫХ ЛАЗЕРОВ}

Издание 2-е, испр. и доп.

\author{
Вакс Е.Д., Лебёдкин И.Ф., Миленький М.Н., \\ Платов Е.С., Раевский Е.В., \\ Сапрыкин Л.Г., Толокнов А.В.
}

В 2016 г. сотрудники НПЦ «Лазеры и аппаратура ТМ» Е.Д. Вакс, И.Ф. Лебёдкин, М.Н. Миленький, Л.Г. Сапрыкин и А.В. Толокнов опубликовали книгу «Резание металлов излучением мощных волоконных лазеров». Резание различных металлов такими лазерами широко распространено в российской промышленности, и это направление, несомненно, будет развиваться и совершенствоваться далее. Но для этого необходимо понимать природу физических процессов, протекающих при лазерном резании, что позволит разработать методы улучшения его качественных показателей и производительности.

Исправленное и дополненное новыми результатами второе издание этой книги посвящено описанию эффективных решений, разработанных и проверенных экспериментально в НПЦ «Лазеры и аппаратура ТМ» в период 2014-2019 гг., для улучшения результатов резания. В данном издании приведены и проанализированы новые дополнительные экспериментальные и теоретические результаты исследований зарубежных фирм, посвященные данной тематике.

Второй и третий разделы книги построены таким образом, чтобы читателям стали более понятны физические процессы лазерного резания и оптимизация условий его проведения. Эти знания позволят реализовать повышенную производительность и достичь улучшенных качественных показателей лазерного резания.

Книга рассчитана на специалистов промышленных предприятий, технологических и научно-исследовательских подразделений и групп, использующих лазерные технологии обработки металлов.

Она также может быть полезна для преподавателей, студентов, операторов лазерных станков и всех «практиков», изучающих или интересующихся тематикой современной лазерной обработки. 